\title{
High Impact Practices-Task sharing for hypertensive disorders in pregnancy: Improving early detection and management of hypertensive disorders in pregnancy
}

Karen Kirk

Population Council

Follow this and additional works at: https://knowledgecommons.popcouncil.org/departments_sbsr-rh

Part of the Maternal and Child Health Commons

How does access to this work benefit you? Let us know!

\section{Recommended Citation}

Kirk, Karen. 2020. "High Impact Practices-Task sharing for hypertensive disorders in pregnancy: Improving early detection and management of hypertensive disorders in pregnancy," Hypertensive Disorders in Pregnancy brief. Washington, DC: Population Council. 


\section{WHAT IS THE HIGH-IMPACT PRACTICE IN MATERNAL HEALTH? \\ Task share key interventions to increase the number of health care workers with the skills to identify high risk women and prevent, detect, and manage wom- en with hypertensive disorders in pregnancy and the postnatal period.}

\section{BACKGROUND}

Maternal mortality disproportionally affects women in lowand middle-income countries (LMICs); global efforts to prevent such deaths - such as the Sustainable Development Goals and Strategies Toward Ending Preventable Maternal Mortality-have brought improvement where possible, but focus is needed on more complex issues with systemic challenges and solutions. Hypertensive Disorders in Pregnancy (HDPs), affect $10 \%$ of women globally and are major contributors to maternal and newborn mortality, morbidity, and disability (Duley, 2009; Say et al., 2014). While the exact cause of eclampsia is unknown, we know how to prevent and manage it. Providing essential services for women at lower levels of the health system is necessary to improve survival rates and quality of life for women who experience HDPs (including eclampsia) and their newborns.

Task sharing essential health services with lower-level cadres can help address insufficient human resources and is recommended for strengthening and expanding the health workforce to increase access to health services. Specific reorganization and decentralization is recommended by the World Health Organization (WHO) because lowerlevel cadres such as auxiliary nurses, community health extension workers (CHEWs) and midwives can providewith targeted mentoring and supervision-detection and management of maternal complications including HDPs. However, quality assurance measures such as training and mentorship are required to maintain quality of care while

\section{KEY POINTS}

- Optimizing available human resources through task sharing can be an effective strategy to increase access to health services.

- Task sharing key services for the prevention, detection and management of hypertensive disorders in pregnancy can help prevent maternal and newborn morbidity and mortality.

increasing access to appropriate services [1-4], informal, unmonitored task-shifting or sharing can negatively impact the quality of care provided [5].

Women with the least access to the health services are most often poor and living in rural areas; particularly in regions of the Global South with inadequate human resources for health [6]. Barriers to accessing maternal health services include the three delays: deciding to seek care, reaching the health facility, and receiving adequate and appropriate care [7]. This HIP brief aims to improve the latter two delays and bring life-saving services closer to the women who need them. Implementing strategic task sharing programs can potentially reduce the barriers that women face when health services are needed. Task sharing can increase the number of staff-including staff at primary health centerswho are able to provide services for HDPs, which ostensibly reduces the delay in reaching a facility that can handle such cases. Further, with more providers trained and capable of providing appropriate care, the delay to receiving care is also reduced.

Task sharing is a promising strategy to improve access to health services by increasing the number of qualified providers of any particular service [8]. Task sharing has been used for HIV/AIDS [9,10], family planning [11], tuberculosis [12] , and other health areas including the management of HDPs [13].

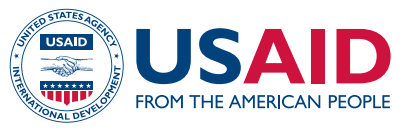
ENDING
The Population Council conducts research and delivers solutions that improve lives around the world. Big ideas supported by evidence:

It's our model for global change. popcouncil.org

(C) 2020 The Population Council, Inc. 
Task shifting and task sharing are often thought to bring cost savings and/or improved efficiency to the health system. A systematic review of the literature found that most cost savings and efficiency gains were found for HIV/AIDS and tuberculosis, perhaps due to the ongoing care and heavy burden of these diseases in LMICs [14]. Little is known about the cost and efficiency implications for task sharing related to HDPs.

Task sharing for HDPs is one of several promising "highimpact practices in maternal health" (HIPs) identified by a technical advisory group of international experts in HDPs, convened by the Ending Eclampsia project. A promising practice has limited evidence, with more information needed to fully document implementation experience and impact. The advisory group recommends these interventions be promoted widely, provided that they are implemented within the context of research and are carefully evaluated in terms of both impact and process. For more information about other HIPs, see https://www. popcouncil.org/research/ending-eclampsia1.

\section{WHY IS THE PRACTICE IMPORTANT?}

Benefits of task sharing, specific to HDPs, exist at different levels of the health system. Task sharing prevention, detection and management with different health cadres has the potential to prevent HDP progression, and reduce associated mortality.

\section{Bringing services closer to women to improve and increase detection, and management of HDP cases}

Insufficient quantity and quality of antenatal care (ANC) and postnatal care (PNC) contacts with health professionals means that women, especially those who may be identified as high risk for HDPs, are not accessing the necessary routine services that could allow for prompt detection and management of HDPs. Putting women at the center of interventions means recognizing the real-world needs and challenges that women face; task sharing enables more providers, closer to women to provide important HDP detection and treatment services that can ultimately save lives.

The WHO recommends a minimum of eight contacts with the health system during pregnancy [15]; in reality, women may attend one or more ANC contact (often in the third trimester) but attending four or more contacts, let alone eight contacts, is less common [16]. Furthermore, routine components of ANC including blood pressure measurement, urine test, information on possible maternal complications, case follow up, etc. that should
Task Shifting: refers to a process of delegation or rational distribution of tasks among health workforce teams. Specific tasks are moved, where appropriate, from highly qualified health workers to health workers with shorter training and fewer qualifications to make more efficient use of the available human resources for health.

Task Sharing: refers to an expansion of the levels of health providers who can appropriately deliver health services. The term is used to emphasize the common performance of the entire clinical task, or key components of it, among teams of different cadres of health workers. Tasks are not taken away from one cadre and given to another, but rather additional cadres are given the capacity to take on identified tasks.

They both reflect the same intention -to include cadres who do not normally have competencies for specific tasks to deliver them and to thereby increase levels of health care access. Both emphasize the need for training and continued educational support of all cadres of health workers in order for them to undertake the tasks they are to perform.

Source: Task Sharing to Improve Access to Family

Planning/Contraception (WHO 2017)

be completed at each contact are not always done [16]. For PNC, women and babies should receive an initial checkup within 24 hours after birth and at least three additional contacts in the six weeks following birth [17]. In LMICs, PNC coverage is consistently low compared to ANC coverage $[18,19]$.

The most common barriers preventing women from accessing services have been well-documented. Many of these obstacles relate to one's ability to physically access health care; cost for transport, distance to facilities, and poor road conditions all influence women's ability and willingness to seek essential services during and following pregnancy [20-22]. Task sharing-whether from hospital providers to primary healthcare providers or from facilitybased providers to community-based providers-brings essential services nearer to the community, reducing barriers, and increasing women's access to care.

Broadly, the global evidence indicates that lower level providers are often competent enough to conduct specific tasks that are normally reserved for higher-level providers. Depending on the level of expertise needed 


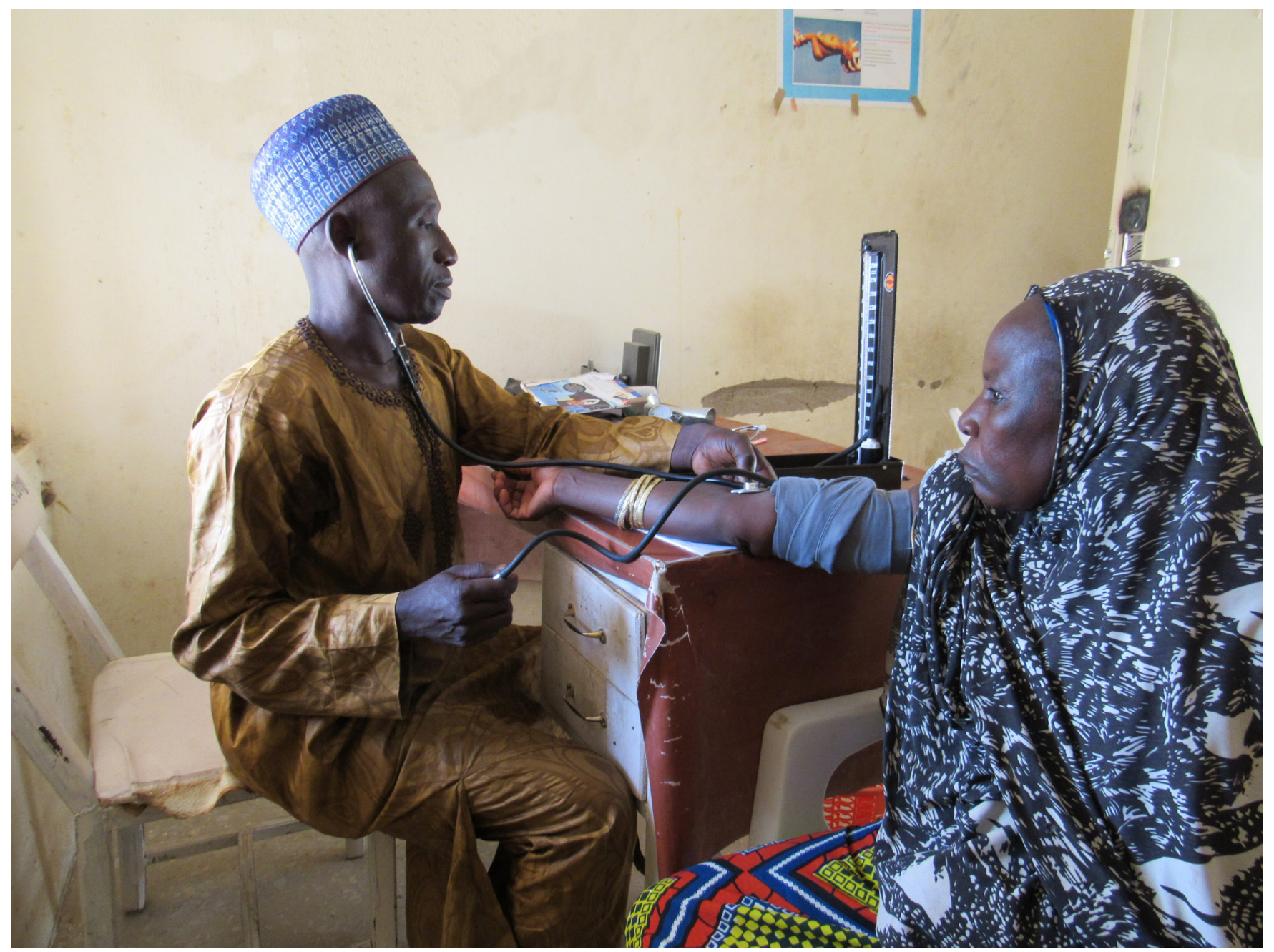

for a particular skill or service, tasks can be shared with lower-level cadres including community health workers (CHWs), primary health care providers (CHEWs, auxiliary nurses, etc.). One study found that it was feasible and acceptable for the lowest-level CHW cadre in Benin to administer Subcutaneous Depot Medroxyprogesterone Acetate (DMPA-SC) thereby increasing community access to family planning [23]. The evidence in support of task sharing family planning spans a variety of modern methods as well as types of health cadres [11,24-26]. Other evidence suggests that task sharing blood pressure measurement and management to lower cadres like nurses, pharmacists, and CHWs is effective [27].

Some early evidence has also emerged specifically related to task sharing for prevention, detection and management of hypertensive disorders in pregnancy [1,28-31].

Bringing routine screening services and acute treatment closer to women, promotes early detection and improved management of HDPs, including close monitoring of blood for any new onset or worsening condition allowing for more prompt medical intervention, or referral when needed.

\section{Optimizing the health workforce that exists to increase access to life-saving HDP services}

In LMICs, multiple factors can impede women from accessing the recommended health services during and following pregnancy. One such contributing factor is an insufficient or inadequately trained workforce. Human resource shortages are known to contribute to provider workload which impacts the care they are able to provide; sharing tasks across multiple cadres can help overcome staffing shortages by increasing the number of available providers who can conduct certain tasks and allow morespecialized providers to focus on more complicated cases; however changes in workload can potentially overburden staff $[32,33]$. 
Routine monitoring of blood pressure early in pregnancy (first trimester) and early identification of high-risk women and women with low calcium intake can promote improved management of high-risk pregnancies with lowdose aspirin or calcium supplementation respectively; reducing the risk of developing pre-eclampsia [34]. Detecting and controlling hypertension in pregnancy can reduce the number of cases that progress to severe preeclampsia/eclampsia.

\section{HOW TO DO IT: TIPS FROM IMPLEMENTATION EXPERIENCE}

\section{Consider the context}

- Assess and clarify the existing policies that govern provision of health services. When considering implementing a task sharing strategy for HDP, it is necessary to understand the governing policies (international, national, sub-national, institutional) related to administration of drugs and provision of care. Nigeria, for example, has the "Standing Order," a national document that guides what health services can be provided by each cadre [33]. Such legal restrictions may be a challenge in proposing task sharing of services.

- Understand the baseline knowledge and skills of each cadre. Different cadres in different contexts have varying levels of training, for example: 2-3 years training for CHEWs in Nigeria, 18 months training for female welfare visitors (FWVs) and three years for Sub-Assistant Community Medical Officer (SACMO) in Bangladesh, 15 months for lady health workers in Pakistan, and three years for midwives, or "sages-femmes" in Senegal. In some contexts, there is variation of experience and training within a particular cadre, as is the case for health extension workers (HEWs) in Ethiopia. Furthermore, providers with the same designation are likely to have different levels of education, medical training, and scope of practice from one context to the next [35]. It's important to focus on the competency, training, and scope of work rather than the name of the cadre in different contexts when deciding what global recommendations to implement.

\section{Identify task or tasks to be shared and by whom}

When considering task sharing, it is critical to first consider the context, the international guidelines, and available evidence [36]. In addition, prior to implementing a task sharing approach, clear job descriptions that incorporate the new task into the health providers expected roles and responsibilities should be developed.

- CHWs can provide essential screening and counseling services to women. These lower cadres can be trained to effectively take medical history and measure vital signs (e.g. blood pressure measurement)[13]. With innovations like the CRADLE blood pressure machine, CHWs can measure women's blood pressure [2], educate them about danger signs in pregnancy, and refer women to a health center, if needed. Using the CRADLE device, blood pressure measurement is simple to perform and understand; the red, yellow, green color indicator clearly translates systolic and diastolic blood pressures into actions. CHWs can be effective at identifying high-risk women or women with hypertension, and can monitor blood pressure levels in women diagnosed with HDP at the community level, thus increasing their exposure to monitoring services and prompt referral should their condition worsen.

- Sharing management of HDP with primary health care providers. PHC providers (e.g. CHEWs, community midwives, SACMOs, and others) are already taking vital signs and examining women during pregnancy; often these providers are able to identify hypertension in pregnancy and must refer women to a physician for treatment. Task sharing for these groups of providers can include treatment (or initial treatment, depending on the context) of hypertension in pregnancy using oral antihypertensive drugs to control high blood pressure.

- PHC providers can initiate immediate management of severe pre-eclampsia/eclampsia with a modified loading dose of magnesium sulphate $\left(\mathrm{MgSO}_{4}\right)$. When a woman arrives at a PHC center with severe pre-eclampsia, it is critical that she receive $\mathrm{MgSO}_{4}$ as quickly as possible to stop the progression of her condition and/or control and prevent seizures associated with eclampsia. Normally, the loading dose of $\mathrm{MgSO}_{4}$ requires intravenous (IV) and intramuscular (IM) injections, which PHC providers are often not trained, skilled, or permitted to perform. Studies show that an IM injection alone can safely and effectively be administered by these providers $[28,37]$.

- Prophylactic treatment using aspirin and/or calcium can help to reduce the risk of developing preeclampsia in women who are high risk. Women who 
FIGURE 1. Tasks related to prevention, detection and management of HDPs and recommendations for task sharing

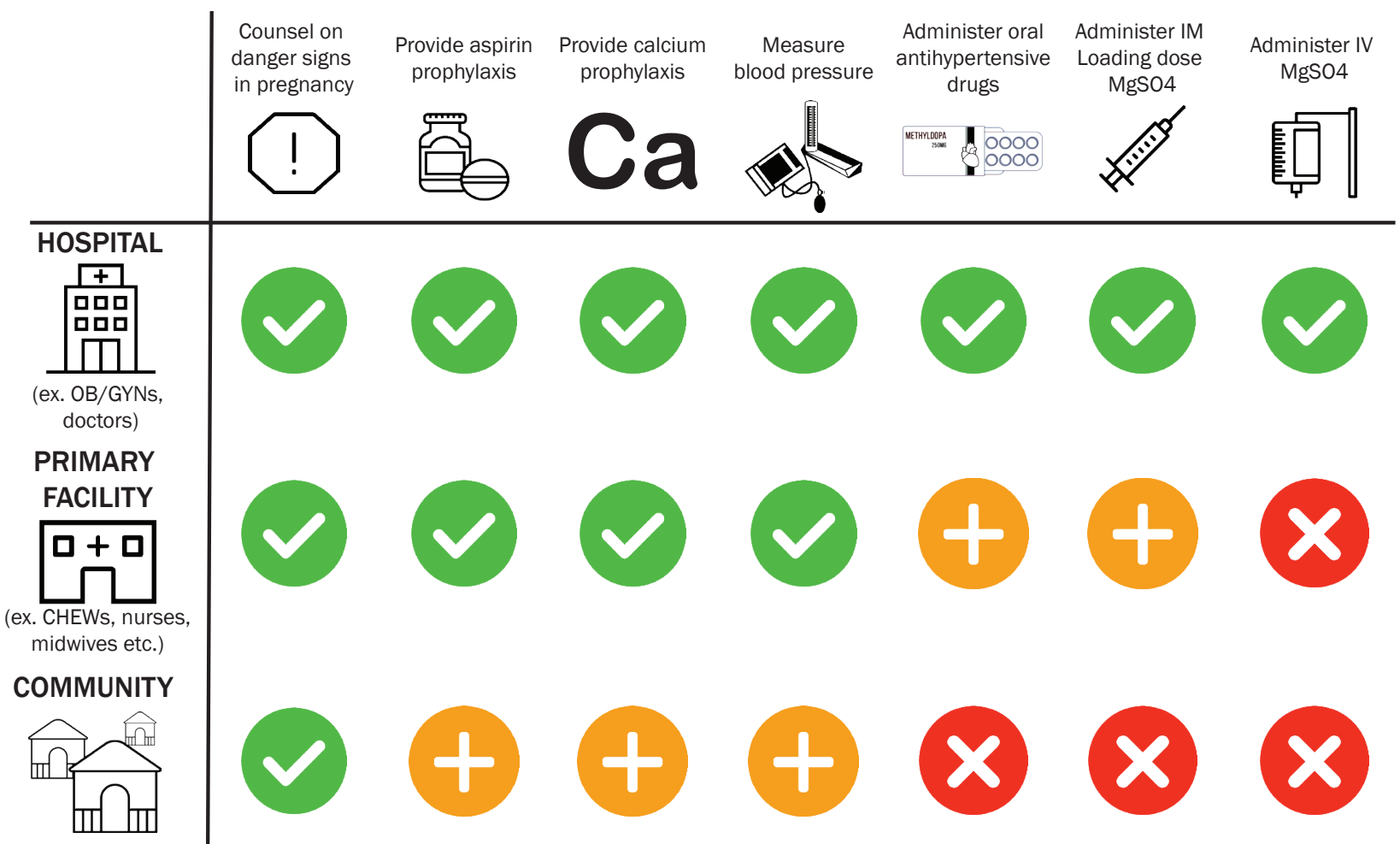

(ex. CHWs, HEWs)

Current Tasks

Recommended for Task Sharing

X Not Recommended for Task Sharing

are at increased risk of developing pre-eclampsia (e.g. those with history of hypertension) could benefit from low-dose aspirin prophylaxis [38]. Calcium prophylaxis can reduce this risk among women with low calcium intake [34].

Improve self-efficacy of providers for new(er) skills related to pre-eclampsia/eclampsia (PE/E) detection and management

- Transfer knowledge and provide support to improve provider competency and capacity. When asking someone to add a new task to their current role and responsibilities, training is required to ensure that the person has the knowledge and skills necessary to correctly and safely carry out that task, understand the risks, and follow up appropriately. Low dose, high frequency trainings and simulations drawing on updated curricula should be used to improve their confidence as well as the technical expertise of providers $[39,40]$. Regardless of the new task, proper training, follow-up training, supervision, and mentorship is required for quality service provision.
HEALTH SYSTEM NEEDS FOR TASK SHARING HDP CARE WORKS BEST IN AN ENABLING ENVIRONMENT THAT INCLUDES:

- Favorable national policy around human resources for health and standardized clinical protocols for distinct cadres

- Stakeholder engagement (including professional associations) throughout developing standards, training curricula, scaling, and institutionalizing

- Initial and ongoing training for providers and their supervisors to promote and maintain newly acquired knowledge, skills and confidence

- Supportive supervision to reinforce technical knowledge, skills and confidence

- Funding (to support maternal health and purchase supplies/medicines for PE/E prevention, detection and management)

- Supply chain for essential equipment and drugs related to $\mathrm{PE} / \mathrm{E}\left(\mathrm{MgSO}_{4}\right.$, antihypertensives, BP machines, dipsticks, stethoscopes etc.) 
- Established, functional referral and counter referral system to ensure prompt and appropriate care based on seriousness and urgency

- Infrastructure to provide health services

- Official and appropriate remuneration for broadening the scope of practice for cadres concerned

\section{FACTORS THAT INHIBIT SUCCESS:}

- Commodity stock-outs preventing necessary interventions

- Lacking oversight and supportive supervision to ensure quality of care maintained for all cadres

- Failure to appropriately compensate and motivate providers to take on additional tasks

- Unsustainable workloads of providers

- Staff turnover and shortages

- Sharing/shifting specific services to cadres that are too low to safely perform them

- Ineffective referral systems leading to lag time in follow up care

\section{PRIORITIES FOR FUTURE RESEARCH:}

- Testing innovative approaches for vital sign measurements in low resource settings

- Strengthened evidence base on which provider cadres are able to effectively carry out specific skills related to HDPs

- Rigorous implementation research to determine best practices (e.g. lowest effective dose for $\mathrm{MgSO}_{4}$ ) to inform task-sharing guidelines and policies

- Cost effectiveness of task sharing aspects of prevention, detection, and management of HDPs to lower levels

- Strategies to effectively scale up successful tasksharing initiatives

\section{TOOLS AND RESOURCES}

- Ending Eclampsia PHC Model Commentary

- Helping Mothers Survive: Pre-eclampsia \& Eclampsia

- The Microlife CRADLE VSA

\section{REFERENCES}

1. Charanthimath U, Vidler M, Katageri G, Ramadurg $\mathrm{U}$, Karadiguddi C, Kavi A, et al. The feasibility of tasksharing the identification, emergency treatment, and referral for women with pre-eclampsia by community health workers in India. Reprod Health. 2018;15(Suppl 1).

2. Nathan $\mathrm{HL}$, Boene $\mathrm{H}$, Munguambe $\mathrm{K}$, Sevene E, Akeju $\mathrm{D}$, Adetoro $\mathrm{OO}$, et al. The CRADLE vital signs alert: qualitative evaluation of a novel device designed for use in pregnancy by healthcare workers in low-resource settings. Reprod Health. 2018;15(1):5.

3. World Health Organisation (WHO). Task sharing to improve access to Family Planning / Contraception. 2017.

4. Firoz T, Sanghvi H, Merialdi M, von Dadelszen P. Preeclampsia in low and middle income countries. Best Pract Res Clin Obstet Gynaecol [Internet]. 2011 Aug [cited 2015 Jun 4];25(4):537-48. Available from: http://www.sciencedirect.com/science/article/pii/ S152169341100054X

5. Ferrinho P, Sidat M, Goma F, Dussault G. Taskshifting : experiences and opinions of health workers in Mozambique and Zambia. 2012;1-8.

6. World Health Organization. Maternal Mortality: Fact Sheet [Internet]. 2018. Available from: https://www. who.int/en/news-room/fact-sheets/detail/maternalmortality

7. Thaddeus S, Maine D. Too far to walk: maternal mortality in context. Soc Sci Med. 1994 Apr;38(8):1091-110.

8. Fulton BD, Scheffler RM, Sparkes SP, Auh EY, Vujicic M, Soucat A. Health workforce skill mix and task shifting in low income countries : a review of recent evidence. 2011;1-11.

9. Zachariah R, Ford N, Philips M, S.Lynch, Massaquoi $M$, Janssens $V$, et al. Task shifting in HIV/AIDS: opportunities, challenges and proposed actions for sub-Saharan Africa. Trans R Soc Trop Med Hyg. 2009;103(6):549-58. 
10. Belayneh Y, Tekola F, Madeo M, Resti C. Task-shifting of HIV/AIDS services down the professional ladder: Current status in Ethiopia and lessons from other African Countries. Ethiop J Heal Dev. 2009;23(3):234-5.

11. Tilahun Y, Lew C, Belayihun B, Lulu Hagos K, Asnake M. Improving Contraceptive Access, Use, and Method Mix by Task Sharing Implanon Insertion to Frontline Health Workers: The Experience of the Integrated Family Health Program in Ethiopia. Glob Heal Sci Pract. 2017 Dec;5(4):592-602.

12. Farley JE, Ndjeka N, Kelly AM, Whitehouse E, Lachman S, Budhathoki C, et al. Evaluation of a nurse practitioner-physician task-sharing model for multidrugresistant tuberculosis in South Africa. PLoS One. 2017;12(8):e0182780.

13. Kinney M V., Smith JM, Doherty T, Hermida J, Daniels K, Belizán JM. Feasibility of community level interventions for pre-eclampsia: perspectives, knowledge and tasksharing from Nigeria, Mozambique, Pakistan and India. Reprod Health [Internet]. 2016;13(1):1-4. Available from: http://dx.doi.org/10.1186/s12978-016-0245-6

14. Seidman G, Atun R. Does task shifting yield cost savings and improve efficiency for health systems? A systematic review of evidence from low-income and middle-income countries. Hum Resour Health. 2017 Apr;15(1):29.

15. World Health Organization. WHO recommendations on antenatal care for a positive pregnancy experience. Geneva, Switzerland; 2016.

16. Benova L, Tunçalp Ö, Moran AC, Campbell OMR. Not just a number: Examining coverage and content of antenatal care in low-income and middle-income countries. BMJ Glob Heal. 2018;3(2):1-11.

17. WHO. WHO recommendations on Postnatal care of the mother and newborn. World Heal Organ [Internet]. 2013;1-72. Available from: http://apps.who.int/iris/ bitstream/10665/97603/1/9789241506649_eng. pdf

18. Langlois É V., Miszkurka M, Zunzunegui MV, Ghaffar A, Ziegler D, Karp I. Inégalités des soins postnatals dans les pays à revenu faible et à revenu intermédiaire: Revue systématique et méta-analyse. Bull World Health Organ. 2015;93(4):259-70.

19. Amouzou A, Mehra V, Carvajal-Aguirre L, Khan SM, Sitrin D, Vaz L. Measuring postnatal care contacts for mothers and newborns: An analysis of data from the MICS and DHS surveys. J Glob Health. 2017;7(2).

20. Geleto A, Chojenta C, Mussa A, Loxton D. Barriers to access and utilization of emergency obstetric care at health facilities in sub-Saharan Africa-a systematic review protocol. Syst Rev. 2018;7(1):1-14.
21. Kyei-Nimakoh M, Carolan-Olah M, McCann $\mathrm{T}$ V. Access barriers to obstetric care at health facilities in sub-Saharan Africa-a systematic review. Syst Rev. 2017;6(1):1-16.

22. Bohren MA, Hunter EC, Munthe-Kaas HM, Souza JP, Vogel JP, Gulmezoglu AM. Facilitators and barriers to facility-based delivery in low- and middle-income countries: a qualitative evidence synthesis. Reprod Health. 2014 Sep;11(1):71.

23. Okegbe T, Affo J, Djihoun F, Zannou A, Hounyo O, Ahounou G, et al. Introduction of community-based provision of subcutaneous depot medroxyprogesterone acetate (DMPA-SC) in Benin: Programmatic results. Glob Heal Sci Pract. 2019;7(2):228-39.

24. Gueye B, Wesson J, Koumtingue D, Stratton S, Viadro C, Talla $\mathrm{H}$, et al. Mentoring, task sharing, and community outreach through the tutoratplus approach: Increasing use of long-Acting reversible contraceptives in Senegal. Glob Heal Sci Pract. 2016;4:S33-43.

25. Charyeva Z et al. Task Shifting Provision of Contraceptive Implants to Community Health Extension Workers: Results of. Glob Heal Sci Pract. 2015;3(3):382-94.

26. Schaefer L. Task sharing implant insertion by community health workers: Not just can it work, but how might it work practically and with impact in the real world. Glob Heal Sci Pract. 2015;3(3):327-9.

27. Anand TN, Joseph LM, Geetha A V., Prabhakaran D, Jeemon P. Task sharing with non-physician health-care workers for management of blood pressure in lowincome and middle-income countries: a systematic review and meta-analysis. Lancet Glob Heal [Internet]. 2019;7(6):e761-71. Available from: http://dx.doi. org/10.1016/S2214-109X(19)30077-4

28. Danmusa S, Coeytaux F, Potts J, Wells E. Expanding Use of Magnesium Sulfate for Treatment of Pre-eclampsia and Eclampsia. 2014;(December).

29. Rawlins B, Plotkin M, Rakotovao JP, Getachew A, Vaz M, Ricca J, et al. Screening and management of preeclampsia and eclampsia in antenatal and labor and delivery services: findings from cross-sectional observation studies in six sub-Saharan African countries. 2018;1-11.

30. Nwala E, Anaba U, Sripad P, Ishaku S, Warren C. Feasibility and Acceptability of Community Health Extension Workers to Identify and Treat Hypertension Associated with Pregnancy: Implementation Research Report. 2019. 
31. Hossain S, Sultana K, Roy S, Sripad P, Warren C. Assessing the Feasibility of Primary Health Care Provider Prescription of Anti-Hypertensive Medication to Pregnant Women in Bangladesh. 2019.

32. Munabi-Babigumira S, Glenton C, Lewin S, Fretheim $A$, Nabudere $H$. Factors that influence the provision of intrapartum and postnatal care by skilled birth attendants in low- and middle-income countries: a qualitative evidence synthesis. Cochrane database Syst Rev. 2017 Nov;11:CD011558.

33. Akeju DO, Vidler M, Sotunsa JO, Osiberu MO, Orenuga EO, Oladapo OT, et al. Human resource constraints and the prospect of task-sharing among community health workers for the detection of early signs of preeclampsia in Ogun State, Nigeria. Reprod Health [Internet]. 2016;13(Suppl 2). Available from: http:// dx.doi.org/10.1186/s12978-016-0216-y

34. World Health Organization. WHO recommendation: Calcium supplementation during pregnancy for the prevention of pre-eclampsia and its complications [Internet]. 2018. 1-51 p. Available from: http://www. ncbi.nlm.nih.gov/pubmed/30629391

35. Mullan F, Frehywot S. Non-physician clinicians in 47 sub-Saharan African countries. Lancet. 2007;370(9605):2158-63.

36. World Health Organization. Optimizing health worker roles to improve access to key maternal and newborn health interventions through task shifting. World Heal Organ [Internet]. 2012;198. Available from: http://scholar.google.com/ scholar?hl=en\&btnG=Search\&q=intitle:health + worker+roles+to+improve+access+to+key+maternal +and+newborn+health+interventions+through+ task+shifting\#0\%5Cnhttp://scholar.google.com /scholar?hl=en\&btnG=Search\&q=intitle:Optimizing thealth
37. Okusanya B, Aigere E, RA OBAEAAIHS. Maternal deaths: initial report of an on-going monitoring of maternal deaths at the Federal Medical Centre Katsina, Northwest Nigeria. J Matern - Fetal Neonatal Med [Internet]. 2013 [cited 2015 Apr 30];26(9):885-8. Available from: http://informahealthcare.com/doi/abs/10.3109/1476 7058.2013.765851

38. Townsend R, Brien PO, Khalil A. Current best practice in the management of hypertensive disorders in pregnancy. Integr Blood Press Control. 2016;9(1):7994.

39. Ugwa E, Otolorin E, Kabue M, Ishola G, Evans C, Oniyire $A$, et al. Simulation-based low-dose, high-frequency plus mobile mentoring versus traditional group-based training approaches on day of birth care among maternal and newborn healthcare providers in Ebonyi and Kogi States, Nigeria; A randomized controlled trial. BMC Health Serv Res. 2018;18(1):4-11.

40. jhpiego. Low Dose, High Frequency: A Learning Approach to Improve Health Workforce Competence, Confidence, and Performance [Internet]. Jhpiego. 2013. Available from: http://www.healthynewbornnetwork. org/resource/low-dose-high-frequency-a-learningapproach-to-improve-health-workforce-competenceconfidence-and-performance/

Acknowledgments: This document was originally drafted by Karen Kirk. Critical review and helpful comments were provided by Deborah Armbruster, Fariyan Fikree, Pandora Hardtman, Emily Hillman, Sharif Hossain, Tracy McClair, Kathryn Mimno, Yordanos B Molla, Joseph Obure, Pooja Sripad, Marianne Vidler, and Charlotte Warren.

For further information please contact us at MNH-PCDC@popcouncil.org

Suggested citation: High-Impact Practices (HIPs) in Maternal and Newborn Health. Task Sharing for hypertensive disorders in pregnancy: improving early detection and management of hypertensive disorders in pregnancy. Washington (DC): Population Council; 2020. Available from: https://www.popcouncil.org/research/ending-eclampsia1.
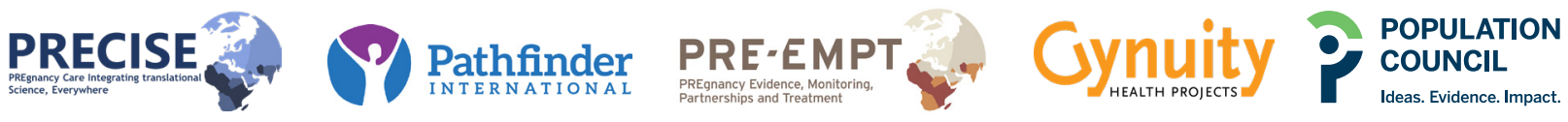